المجلة الدولية للدراسات التربوية والنفسية

بحث رقم 12

المجلد التاسع، العدد الثالث، 933:920 حزيران (2021)

\title{
مستوى التوافق الزواجي لدى عينة من المتزوجين في سلطنة عُمان وعلاقته بالمتغيرات الديموغرافية
}

أحمد "محمد جلال" الفواعير

أستاذ مشارك- كلية العلوم والآداب جامعة نزوى - سلطنة عُمان fawair@unizwa.edu.om
إيمان حمد خلفان المقبالي باحثة اجتماعية- كلية العلوم والآداب جامعة نزوى - سلطنة عُمان 


\title{
مستوى التو افق الزواجي لدى عينة من المتزوجين في سلطنة عُمان وعلاقته بالمتغيرات الديموغر افية
}

\author{
إيمان حمد خلفان المقبالي \\ باحثة اجتماعية- كلية العلوم والآداب- جامعة نزوى- سلطنة عُمان \\ أحمد "محممد جلال" الفواعير \\ أستاذ مشارك- كلية العلوم والآداب- جامعة نزوى- سلطنة عُمان
}

fawair@unizwa.edu.om



تهدف الدراسـة الحالية إلى التعرف على مستوى التوافق الزواجي لدى عينة من المتزوجين في سلطنة عمان، والبالغ عددهم (540) فرداً

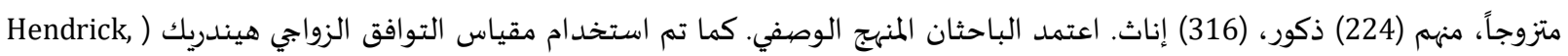
1988)، وأظهرت نتائج الدراسة مستوى مرتفع من التوافق الزواجي، كما أظهرت فروق دالة في مستوى التوافق الزواجي تبعاً لمتغير الجنس المنس


لمتغير العمر وعدد الأبناء. الكلمات المفتاحية: التوافق الزواجي؛ الأسرة؛ الزواج؛ العلاقات الزوجية؛ المتزوجون.

الزواج هو عقد بين رجل وامرأه، وهو النظام الذي خلقه الله، وحثت عليه الشريعة الإسلامية كما توضحاء الآية الكريمة "ومن آياته أن خلق لكم من أنفسكم أزواجاً لتسكنوا إليها، وجعل بينكم موددة ورحمة، إن في ذلك لآيات لقوات وهو يتفكرون" وهو الطريقة التي رضي بها المجتمع، وأقرها لتنظيهم

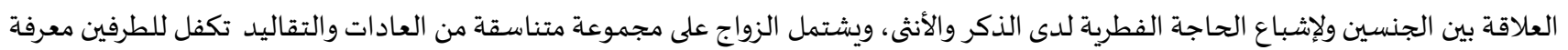
واجباتهما وما سيترتب عليهما من مسؤوليات مستقبلياه، وكذلك تكفل لهما معرفة حقوق كل منهما من الطرف الآخر حتى يعيشا بصوره متوافقة

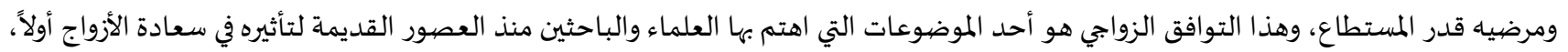

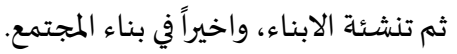


ما يؤذياه، أو يفسد علاقتاء باء أو بأسرتيهما (الداهري، 2008). وقد أورد سبينر (Spanier, 1967) في تحقيقه العديد من التعاريف التي تم استخد امها خلال السنوات الخمس والأربعين الماضية، كتعريف كوتريل (Cottrell, 1933) للتوافق الزواجي بأنه عملية يحاول فيها الأزواج إعادة تمثيل المواقف التهائ التي حصلوا عليها في عوائلهم السـابقة، وتعريف لوك و ويليامسـون (locke and Williamson, 1958) للتوافق الزواجي بأنه الميل الم تجنب أو حل النزاعات، 
والشعور بالرضا عن الزواج، وعن الشريك، وتقاسم المصالح والأنشطة المشتركة، وتحقيق التوقعات الزوجية، وهنالك تعريف آخر للتوافق الزواجي لباورمان (Bowerman, 1964) بأنه السلوك الذي يعمل على تقليل الاختلافات بين الزوجين فيما يتعلق بحالة زوجياة معينة.


التوافق الزواجي من أكثر المفاهيم استخداماً في الزواج ورعاية الأسرة، ويتميز بوفرة التعريفات التي يصعب تحديدها حتى من العلماء انفسهم حيث لا

يستطيعون تحقيق توافق في الآراء حول تعريف المفاهيم وتشغيلها واستخد اهيها (Spanier, 1967). يتضمن مفهوم التوافق الزواجي جوانب كثيرة منها السعادة الزوجية، الرضا الزواجي، التفاعل الزواجي، والنجاح الزواجي، وتستخدم هذه

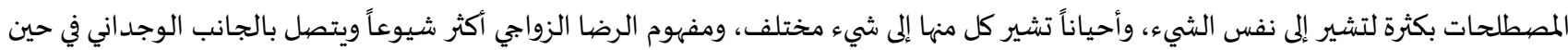
مفهوم التوافق الزواجي أكثر عموماً ويتصل بالجانب السلوكي، بينما التفاعل الزواجي فهو التأثير المتبادل بين زوجين، وتتحقق السعادة الزوجية عندما

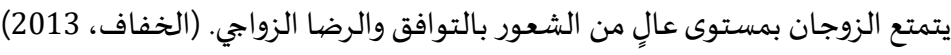
العوامل المؤثرة في التو افق الزواجي

هناك ثلاث مجموعات أساسية من العوامل المؤثرة، أطلقت على المجموعة الأولى اسم العوامل اللوجيستيكية وتتمثل في عدة أمور منها مدة

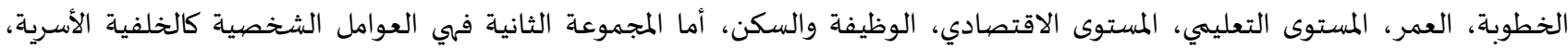
والصحة النفسية والجسمية، والمجموعة الثالثة هي المجموعة التفاعلية وتتمثل في العوامل العاطفية والسلوكية كالشعور بالحب والثقة المتبادلة

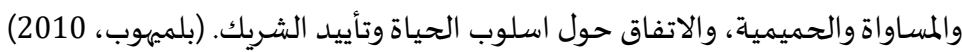
حاول العديد من علماء النفس والاجتماع والباحثين الكشف عن تلك العوامل المسـاعدة في تحقيق السعادة الزوجية، والتوافق الزواجي،

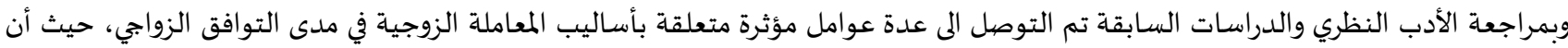
الأساليب غير السوية كالتسلط والنبذ والقسوة والإهمال والتدليل تلعب دور في سوء التوافق الزواجي، بينما مراعاة المشاعر والمرونة في التعامل تزيد

من التكيف بين الزوجين. (زعتر، 2000) تعتبر الشخصية والعوامل الوراثية، واختلاف التنشئة، وكذلك الجانب العاطفي والجنسي والجانب الاقتصادي، كلها عوامل مؤثرة في التوافق الزواجي، كذلك طفولة الزوجين، وسن الزواج، وتدخل الأهل، والإنجاب من ضمن تلك العوامل. (عبيد، 2014)

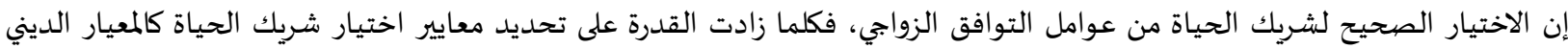


أما سوء التوافق الزواجي فقد تعددت البحوث والدراسات حول العوامل المسببة له، وطرحت تحت مسميات المات منها: أسباب التفكك الأسري، أسباب الخلافات الزوجياة، أسباب الطلاق، معوقات التوافق الزواجي، إلا أهها كانت تدور حول محور واحد وهو عوامل وأسباب سوء التوافق الزواجي.

(الراشد، 2016)

فيمكن أن يكون أداء الدور لأحد الزوجين غير متفق مع توقعات الطرف الآخر، وتكون العادات والقيم والمعايير والرغبات الشخصية للطرفين في

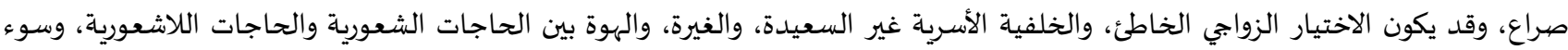
التوافق الجنسي، كلها من عوامل سوء التوافق الزواجي، وكذلك الفرق الكبير في العمر يؤدي إلى سوء الفهم في الكثير من المجالات مما يؤدي إلى سوء التوافق الزواجي، والتباين الكبير في المستوى التعليمي بين الزوجين يؤدي الى الفتور وضعف التيون التفاعل مما يؤدي إلى التفكك والانفصال، والاختلاف

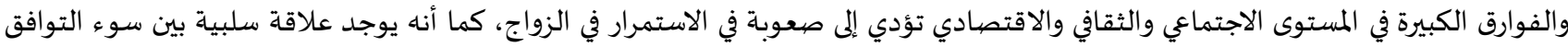

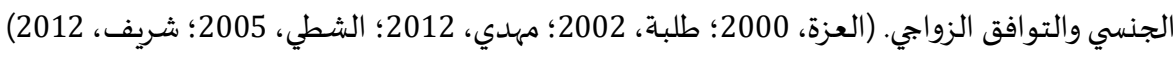

مجالات التو افق الزواجي

للتوافق الزواجي مجالات عديدة تم ذكرها في عدة دراسات كدراسة كل من (الداهري، 2008؛ مؤمن، 2008؛ البلوي، 2015؛ صحاف، 2015؛

حولي، 2019) وهي كالتالي:

1. المجال الاجتماعي: فالشخص المتوافق اجتماعياً هو الذي يسلك وفقاً للأساليب الثقافية السائدة في مجتمعة. 2. المجال الاقتصادي: حين يكون مصدر الدخل مشترك بين الزوجين فإن هذا الدخل يسهم في استمرار العلاقة حتى لو كانت الروابط الزوانية الزوجية

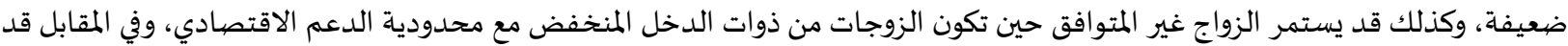

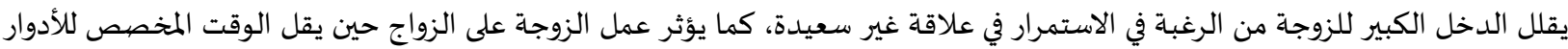
الأسرية.

3. المجال العاطفي: ويعني الشعور بالحب والمودة والاعتبار والتقدير والارتباط العاطفي والنفسي المتبادل بين الزوجين. 
4. المجال الجنسي: ويعني فهم ومعرفة وإدراك معنى الجنس ودوافعه وغاياته وأهدافه، وأن يسعى كلا الزوجين لمعرفة ما يرضي شريكه لتكوين مفهوم مشترك وأسلوب متناسب ليستطيع كل واحد منهما من إشباع رغبات الطرف الآخر.

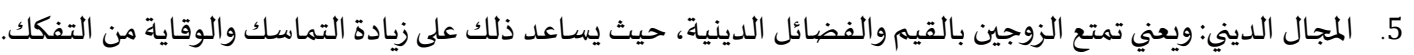

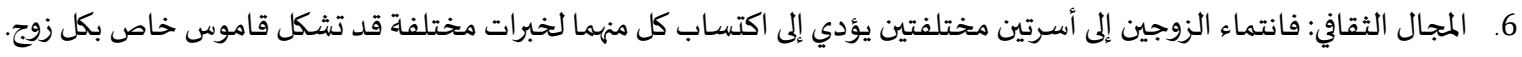

تفسير التو افق الزواجي حسب نظرية التبادل الاجتماعي يعتبر هومانز (Homans) من أوائل علماء النفس الاجتماعي الذين نظروا للسلوك الإنساني على أنها علاقة متبادلة، وطور نظرية أطلق عليها

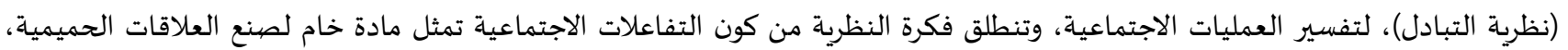

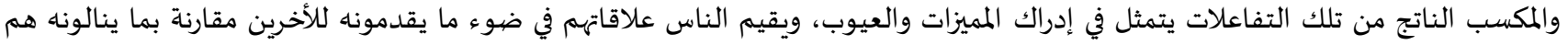

بالمقابل، ويعتبر التوافق الزواجي إدراك الزوجين للمكاسب التي تعود عليه من العلاقة أو المساهمات التي يقدمها للعلاقة الزوجية. (عواودة، 2019)

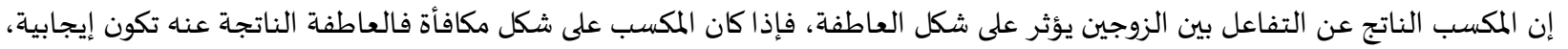

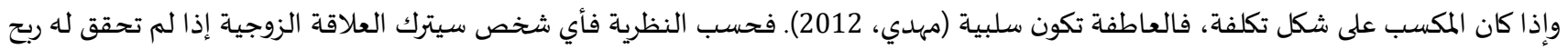

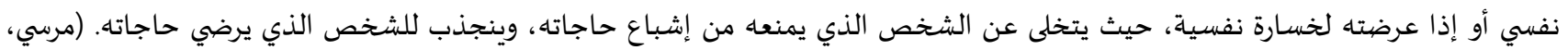

بينما يمكن أن يستمر الفرد في علاقة زوجية غير مرضية في حالة وجود حواجز قوية تجعل من الطلاق أمراً صعباً، كأن تكون البدائل لهذه



الدراسـات السـابقة: تعددت الدراسات التي تناولت التوافق الزواجي، حيث استطاع الباحثان الحصول على مجموعة منها سواء في البيئة العمانية أو العربية أو الأجنبية. فقد أظهرت دراسـة الإبراهيم (2007) العلاقة بين التوافق الزواجي والمهارات الزوجية وبعض المتغيرات الديموغرافية، على عينة مكونه من (510)


الفعال، والتعبير العاطفي، كما أظهرت النتائج أن النساء المتزوجات العاملات في القطاع التربوي يتمتعن بالتوافق الزواجي في المجال النهال النفسي



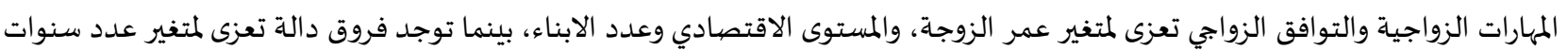

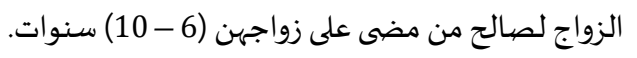
بحثت دراسة الجمالي(2008) تأثير عدد من المتغيرات وهي عمر الزوجين ومدة الزواج وإنجاب الأطفال على درجة التوافق الزواجي، وطبقت الدراسة

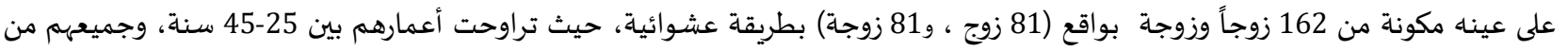
العاملين في المؤسسات الحكومية بمحافظة مسقط، واستخدمت مقياس التوافق الزواجي الذي أعدته الباحثة، ويتكون من (40 مفرده) وأظهرت



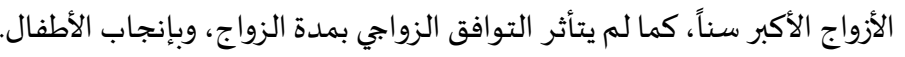
في حين هدفت دراسة التباوي (2012) إلى التعرف على التوافق الزواجي وعلاقته بضغوط العمل، وعلى العلاقة الارتباطية بين التوافق الزواجي

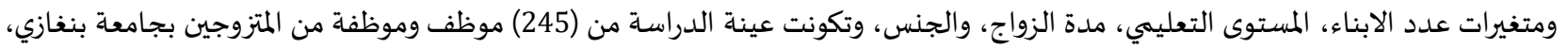

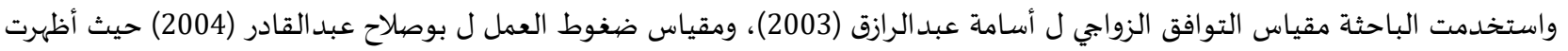

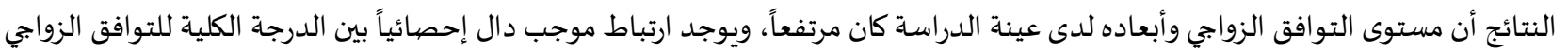
وأبعاده وضغوط العمل، كما بينت النتائج عن عدم وجود فروق دالة إحصائية بين التوافق الزواجي وكل من (الجنس، المستوي التعليمي، ومدة التوائ

الزواج، وعدد الأطفال).

جاءت دراسة الهنائي (2013) للتعرف على بعض من العوامل المسهمة في سوء التوافق الزواجي كما يدركها القائمون على لجان التوفيق والمصالحة

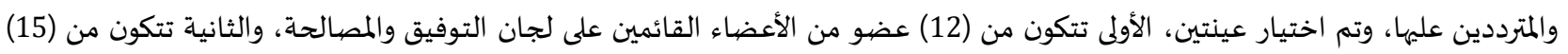

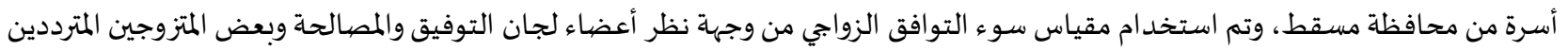

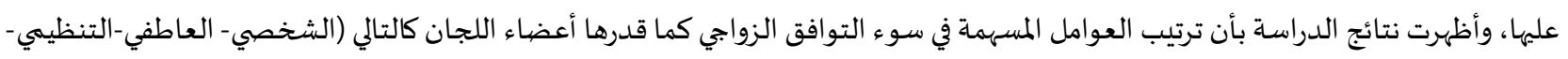
الجنسي)، أما ترتيب العوامل كما قدرها المتزوجين كالتالي (العاطفي- التنظيمي- الشخصي- الجنسي). 
• كما قامت دراسـة الخطايبة (2015) بالتعرف على مقومات التوافق الزواجي لدى عينة مكونه من (388) زوجاً وزوجة من العاملين في المدارس

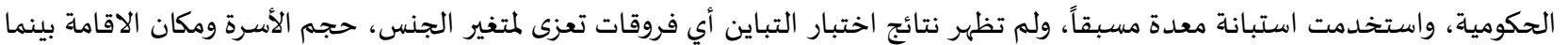


• كما هدفت دراسة صحاف (2015) إلى بحث التوافق الزواجي وعلاقته بالاستقرار الأسري لدى عينة من المتزوجين بمدينة مكة المكرمة، كما هدفت إلى التحقق من وجود فروق في التوافق الزواجي تبعاً لاختلاف المستوى الاقتصادي، والعمر، والمستوى التعليمي، وتم اختيار عينة مكونه من (459) زوج وزوجة، منهم (213) زوجة، و(246) زوج من مدينة مكة المكرمة، واستخدمت الباحثة مقياس التوافق الزواجي من إعداد (العنزي، 2010)، ومقياس الاستقرار الأسري من إعداد (محتار، 1999)، وأظهرت النتائج وجود علاقة ارتباطية موجبة بين التوافق الزواجي وجميع أبعاد الاستقرار

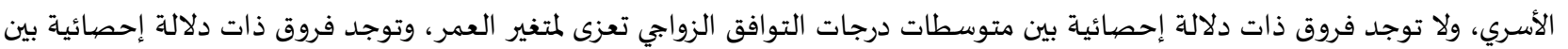
متوسطات درجات التوافق الزواجي تعزى لمتغير المستوى الاقتصادي للزوج في اتجاه دخل الزوج أقل بكثير من مستوى دخل الزوجة، كما توجد

فروق ذات دلالة إحصائية بين متوسطات درجات الاستقرار الأسري لدى مرتفعي ومنخفضي التوافق الزواجي لصالح مرتفعي التوافق الزواجي. قامت دراسة القضاة (2016) بتقصي العلاقة بين المهارات الزوجية والتوافق الزواجي، وتكونت العينة من (173) سيدة متزوجة حديثاً في مدينة عمان بطريقة العينة المتاحة، واستخدم مقياسي المهارات الزواجية والتوافق الزواجي من إعداد الباحثة، وبينت النتائج وجود علاقة ارتباطية طردية



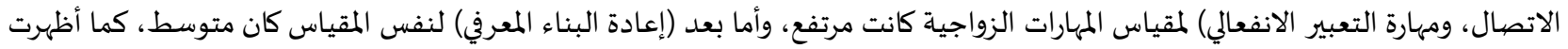


امتلاك المهارات الزواجياة، وفي مستوى التوافق الزواجي، وعدم وجود فروق ذات دلالة إحصائية في امتلاك المهارات الزوجية وفي مستوى التوافق الزواجي تعزى لمتغير المؤهل التعليمي أو عمل الزوجة. سعت دراسـة قمرة (2019) للتعرف على العلاقة بين التوافق الزواجي ومعايير اختيار شريك الحياة، وتم جمع البيانات من عينة عشوائية مكونة من (123) أسرة من خلال استبيان البيانات العامة، واستبيان التوافق الزواجي، واستبيان معايير اختيار شريك الحياة، وأظهرت النتائج أنه كلما

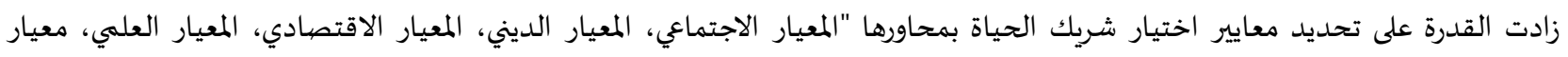
الشخصية، معيار الوظيفة" كلما زاد التوافق الزواجي، كما أظهرت النتائج أن تعليم الزوج كان من أكثر العوامل المؤثرة على التوافق الزواجي يليهاه

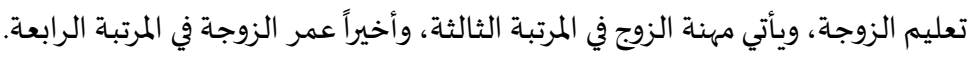

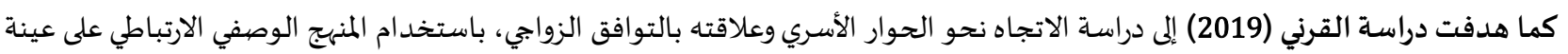
مكونة من (217) زوجاً وزوجة، وقام الباحث بتطوير مقياس التوافق الزواجي من إعداد فرج وعبداللة (1999) والذي استخدماه العمودي (2001)


الحوار الأسري وأبعاده. في حين قامت عواودة (2019) بدراسة العلاقة بين المهارات الزواجية وعلاقتها بالرضيا الزواجي لدى المتزوجات حديثاً في محافظة رام الله والبيرة، واستخدمت الباحثة المنهج الوصفي الارتباطي مع عينة مكون من (10065)، من المتزوجات حديثاً، وأظهرت النتائج أن الدرجة الماتئ الكلية للمهارات



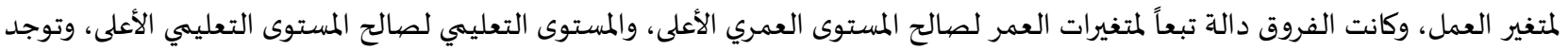

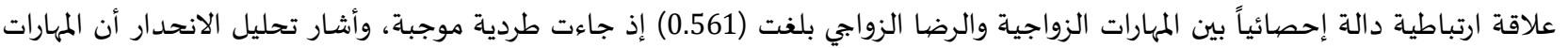
الزواجية تتنبأ بالرضا الزواجي، إذ فسرت المهارات الزواجية (33.2\%) من التباين في مستوى الرضيا الزواجي.

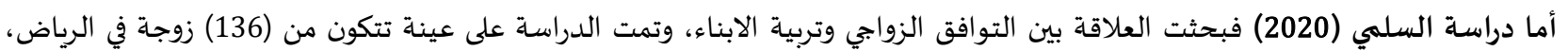
ولتحقيق أهداف الدراسة استخدمت استبانة مقسمة إلى عدة محاور (التوافق الفكري، التوافق الاجتماعي، التوافق النفسي، تربية الابناء)،

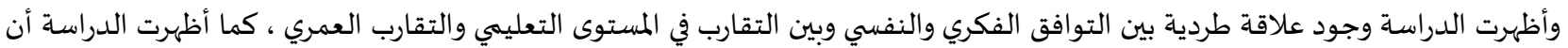

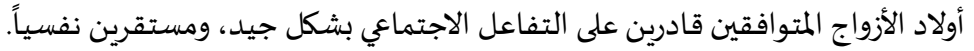

مشكلة الدراسـة: بالرجوع لنسب الطلاق في السلطنة اتضح أن تلك النسب في ازدياد من سنة 2015 إلى سنة 2017، ثم انخفضت مع انخفاض عدد وثائق الزواج

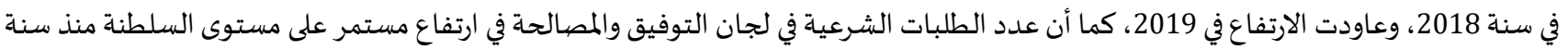
2015 إلى سنة 2019 ، كما بينتها الإحصيائيات. (وزارة العدل، 2020) 
فظهرت الحاجة لدراسـة التوافق الزواجي ومعرفة أثر بعض المتغيرات التصنيفية عليه، لزيادة رفاهية المجتمع من جهة عن طريق استغلال النتائج

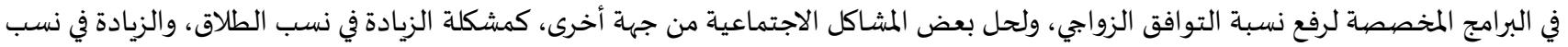
الدعاوي الشرعية في المحاكم ولجان التوفيق والمصالحة.

أسئلة الدراسـة:

1. ما مستوى التوافق الزواجي لدى عينة من المتزوجين في سلطنة عمان؟ 2. هل توجد فروق ذات دلالة إحصائية في مستوى التوافق الزواجي تعزى للمتغيرات الديموغرافية (الجنس، العمر، عدد الابناء، عدد سنوات

الزواج)

أهداف الدراسـة: يهدف البحث الحالي إلى ما يلي:

1. التعرف على مستوى التوافق الزواجي لدى عينة من المتزوجين في سلطنة عمان.

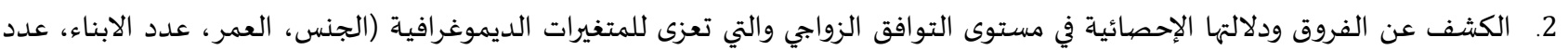

سنوات الزواج).

$$
\text { أهمية الدراسة: }
$$

أولاً: الأهمية النظرية:

إن دراسة التوافق الزواجي له أهمية كبيرة في مجال الإرشاد الزواجي، حيث يوجه اهتمام القائمين لوضع توصيات من شأنها رفع مستوى التوافق

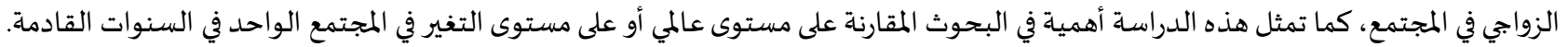
ثانياً: الأهمية التطبيقية:

تكمن الأهمية التطبيقية لهذه الدراسة في إمكانية التخطيط لبناء برامج وتقنيات لرفع مستوى التوافق الزواجي، وبناء برامج إرشاد جمعي


الخصائص السيكومترية المطبقة على البيئة العمانية.

حدود الدراسة: الحدود الموضوعية: التوافق الزواجي لدى عينة من المتزوجين في سلطنة عمان من محافظة البريمي الحدود الزمانية : تم تطبيق هذه الدراسة خلال شهر نيسان (أبريل) من العام 2020 الحدود المكانية: سلطنة عمان- محافظة البريمي. الحدود البشرية: تكمن الحدود البشرية في العينة التي طبقت عليها الدراسة من المتزوجين في محافظة البريمي بسلطنة عمان.

مصطلحات الدراسـة: Marital Adjustment التو افق الزواجيات الدراسي: يعد لوك ووالانس (locke and Wallace, 1959) من أوائل العلماء الذين عرّفوا التوافق الزواجي ووفقاً لتعريفهما فالتوافق الزواجي هو " تبني كل

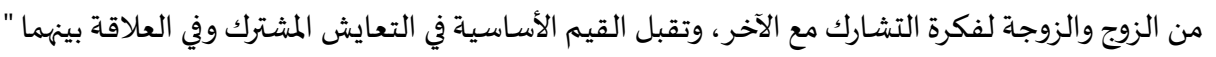

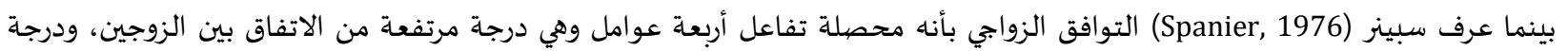
منخفضة من التفاعل السلبي والشجار والخصام، ودرجة مرتفعة من الأعمال المشتركة، وعدد قليل من المشكلات ذات العلاقة بالجانب العاطفي والجنسي. أما الباحثان فيعرفان التوافق الزواجي نظرياً بأنه: قدرة الزوجين على الاستمرار في حياة زوجية متكيفة ومتوائمة وتخطي ما يواجهانه من خلافات


منهيج الدراسة:

بناءً على مشكلة الدراسة وتسـاؤلاتها تم استخدام المنهج الوصفي لملائمته لطبيعة الدراسة الحالية حيث يدرس الظاهرة كما هي في الواقع ويصفها وصفا دقيقا ويعبر عنها تعبيراً وصفياً وكمياً. 
تكون مجتمع الدراسة من جميع المتزوجين/ المتزوجات في سلطنة عمان خلال فترة تطبيق الدراسـة، وذلك في شهر أبريل 2020 والذي بلغ عددهم وفقاً لإحصيائياًت وزارة العدل (9792) فرداً متزوجاً.

عينة الدراسـة:

اختار الباحثان عينة استطلاعية عشوائية قوامها (42) زوجاً وزوجة من مجتمع الدراسة الأصلي، وطبقت عليها أداة الدراسة بهدف التحقق من

مناسبتها لأفراد العينة الأساسية، واستخراج خصائصها السيكومترية (الصدق والثبات) بالطرق الإحصائية الملائمة.

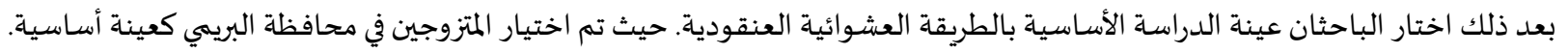

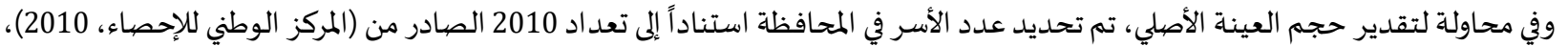

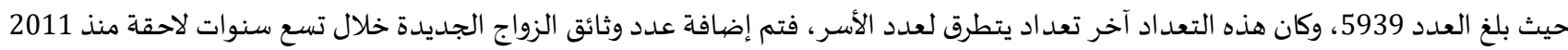
إلى 2019، وطرح من الناتج عدد وثائق الطلاق الجديدة خلال نفس السنوات والتي تم الحصول عليها من إحصائياًت (وزارة العدل، 2020) وذلك

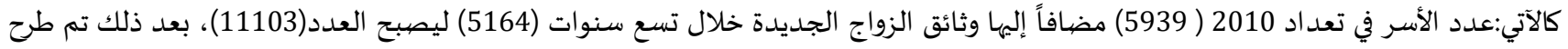


عينة الدراسـة الذين أجابوا على أداة الدراسة من (540) زوجاً وزوجة من محافظة البرات البيمي بسلطنة عمان. وبذلك تمثل عينة الدراسة (5.5 \%). أداة الدراسـة:

استخدم الباحثان في هذه الدراسة مقياس التوافق الزواجي لهيندريك (Hendrick, 1988)، وهو نسخة مطورة من مقياس Dyadic Adjustment)

لسبينر والذي يعتبر من أوسع المقاييس استخداماً، وتم تطوير المقياس ليتكون من 7 فقرات. وقد تم اختيار المقياس للأسباب التالية: 1. مناسبة المقياس لأهد اف الدراسة. 2. ت وضوح فقرات المقياس ومناسبتها لعينة الدراسـة. 3. تمتع المقياس بخصائص سيكومتريه جيدة. 4. استخدام المقياس بدراسات سابقة أجنبية. 5. ترجمة المقياس لعدة لغات. 6. قلة وجود مقاييس تقيس مستوى التوافق الزواجي ومطبقة في البيئة العربية.

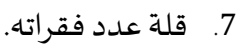

مرت عملية ترجمة مقياس التوافق الزواجي ل هيندريك (Hendrick, 1988) بعدة اجراءات كما يأتي:

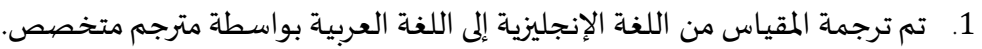
2. 3. قورنت النسخة الإنجليزية الأصلية مع النسخة الإنجليزية المترجمة، ونتيجة لذلك أجريت بعض التعديلات الطفيفة في بعض الفقرات أو الكلمات. 4. استخراج الخصائص السيكومترية للمقياس بصورته العربية. صبدق المقياس:

تم حساب صدق المقياس بطريقتين: الصيدق الظاهري وصددق الفقرات وهي كما يأتي:

أولاً: الصبدق الظاهري:

للتحقق من الصدق الظاهري تم عرض المقياس في صورته الأولية على 10 محكمين مختصين في الإرشاد النفسي، والصحة النفسية، وعلم النفس التربوي، وطلب منهم إبداء آرائهم، وإضافة التعديلات المناسبة. وقد أجمع المحكمون على ملائمة فقرات المقياس لغرض الدراسة، وانتمائها للبعد الذي تندرج تحته، وسلامة الصياغة اللغوية، وقد كان هناك إجماع على وضورج الفقرات إتهات وملائمتها وسلامتها اللغوية. ثانيًا: صبدق الفقرات تم حساب صدق الفقرات من خلال حساب معاملات ارتباط بيرسون لمعرفة درجة ارتباط كل فقرة من فقرات المقياس مع الدرجة الكلية للمقياس كما هو موضح في الجدول (1). 
جدول (1): معامل ارتباط بيرسون بين درجة كل فقرة من فقرات مقياس التو افق الزواجي والدرجة الكلية للمقياس (ن =42)

\begin{tabular}{cc}
\hline رقم الفقرة & 1 \\
\hline $0.872^{* *}$ & 2 \\
$0.834^{* *}$ & 3 \\
$0.773^{* *}$ & 4 \\
$0.609^{* *}$ & 5 \\
$0.800^{* *}$ & 5 \\
$0.782^{* *}$ & 6 \\
$0.767^{* *}$ & 7
\end{tabular}

(0.01) (2*) إحصائياً عند مستوى دلالة

يتضح من جدول (1) أن جميع فقرات مقياس التوافق الزواجي تتمتع بمعامل ارتباط جيد ودال إحصائياً عند مستوى دلالة (0.01)، مما يشير إلى معامل ارتباط مناسب للفقرات ثبات المقياس: للتحقق من ثبات مقياس التوافق الزواجي، تم حساب معامل الثبات للمقياس ككل باستخدام معامل ألفا لكرونباخ (Cronbach's Alpha). حيث


تصحيح المقياس: يشمل المقياس المستخدم في هذه الدراسة (7) فقرات، صيغت 5 فقرات منها بشكل إيجابي، وضع لها تدرج خماسي كالآتي (كبيرة جدأ = 5، كبيرة


4، قليلة جداً = 5). ولأجل استخراج الدرجة الكلية للمقياس يتم حساب المتوسطات الحسابية للمقياس ككل ولكل فقرة من فقرات المقياس، وتُشير الدرجة العالية

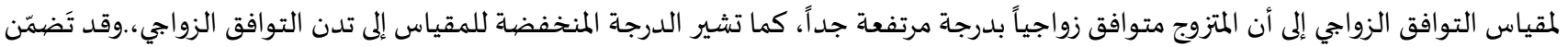
المقياس تعليمات متعلقة بالمحافظة على السرية، وعدم استخدام المعلومات لأغراض أخرى غير البحث العلمي.

\section{النتائج ومناقشتها:}

\section{1. مستوى التو افق الزواجي لدى عينة من المتزوجين في محافظة البريمي} للإجابة على التساؤل الأول للدراسة والذي ينص الدئ على: ما مستوى التوافق الزواجي لدى عينة من المتزوجين في محافظة البريمي، تم حساب


تم حساب (الحدود الدنيا والعليا)، ثم حساب المدى (أعلى قيمة ـ أقل قيمة ) أي (5 - 1 = 4)، وللحصول على طول الفئة تم تقسيماء على أكبر قيمة في

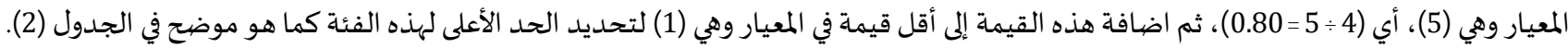

\begin{tabular}{|c|c|c|}
\hline المستوى & المتوسط الحسابي & م \\
\hline منخفض جداً & $1.8-1$ & 1 \\
\hline منخفض & $2.61-1.9$ & 2 \\
\hline متوسط & $4.23-2.62$ & 3 \\
\hline مرتفع & $4.23-3.43$ & 4 \\
\hline مرتفع جداً & $5-4.24$ & 5 \\
\hline
\end{tabular}

يوضسح الجدول (3) المتوسطات الحسابية والانحرافات المعيارية لمستوى فقرات مقياس التوافق الزواجي، وللمقياس ككل. 
جدول (3): المتوسطات الحسابية والانحر افات المعيارية لمستوى فقرات مقياس التو افق الزواجي

\begin{tabular}{|c|c|c|c|c|c|}
\hline  & الترتيب & الانحراف المعياري & المتوسط الحسابي & 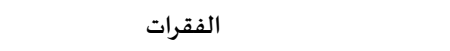 & 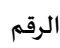 \\
\hline 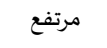 & 6 & 1.05 & 3.71 & ما مدى تلبية شريك حياتك لاحتياجاتك؟ & 1 \\
\hline 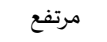 & 4 & 1.08 & 3.90 & بشكل عام، ما مدى رضاك عن علاقتك؟ & 2 \\
\hline 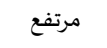 & 3 & 1.02 & 3.94 & ما مدى جودة علاقتك مقارنة مع الأغلبية؟ & 3 \\
\hline 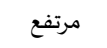 & 2 & 1.25 & 3.99 & كم مره تمنيت أنك لم تخض هذه العلاقة؟* & 4 \\
\hline متوسط & 7 & 1.15 & 3.32 & إلى أي مدى توافقت علاقتك مع توقعاتك الأصلية؟ & 5 \\
\hline 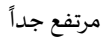 & 1 & 0.94 & 4.33 & ما درجة حبك لشريك حياتك؟ ل & 6 \\
\hline 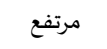 & 5 & 1.10 & 3.75 & كم عدد المشاكل الموجودة في علاقتك؟ * & 7 \\
\hline  & & 0.88 & 3.85 & مقياس التو افق الزواجي & \\
\hline
\end{tabular}

أوضحت النتائج أن مستوى التوافق الزواجية لدى عينة من المتزوجين في محافظة البريمي كان مرتفعاً، حيث بلغ المتوسط الحسابي (3.85)، وبانحراف معياري (0.88)، كما يتضح من الجدول أن العبارة رقم 6 حصلت على أعلى متوسط حسابي وبمستوى مرتفع جداً، والعبارة رقم 5 حصلت

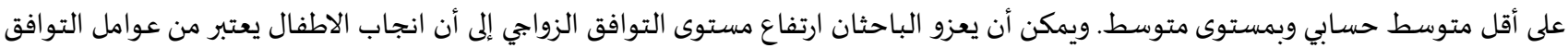

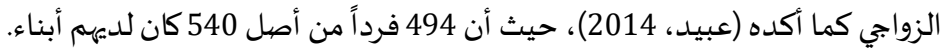
كما يعزو الباحثان ارتفاع مستوى التوافق الزواجي إلى طول فترة الزواج، فقد تبين أندان أكثر من (432) فرداً من أصل العين أعينة الكلية المكونة من (540) قد مر على زواجهم ما يزيد عن خمس سنوات. ويتفق ذلك مع ما توصل إليه كل من (القضاة، 2016؛ الخولي، 2019) بأن المشكلات الزواجية

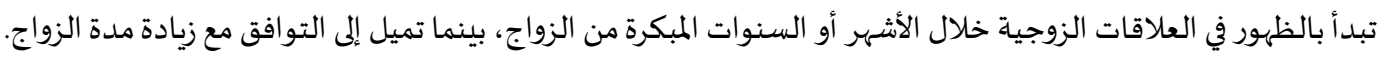
كما يمكن أن يكون للوضع الإقتصادي الجيد لدى المجتمع العماني مقارنة مع المجتمعات الأخرى غير الخليجية دور كبير في زيادة نسبة التوافق

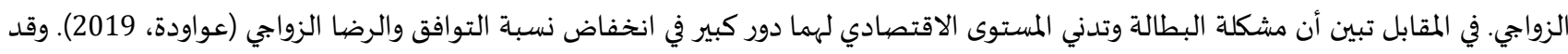
اتفقت نتائج الدراسـة الحالية مع دراستي (التباوي، 2012) و (القضاة، 2016) اللتان أشارتا إلى أن مستوى التوافق الزواجي تراوح ما بين مرتفع ومرتفع

2. الفروق ودلالتها الإحصائية في مستوى التو افق الزواجي والتي تعزى للمتغيرات الديموغر افية (الجنس، العمر، عدد الابناء، عدد سنوات

للإجابة على التساؤل الثاني للدراسة والذي ينص على: هل توجد فروق دالة إحصائياً للتوافق الزواجي تعزى لمتغير الجنس، العمر، عدد الابناء،

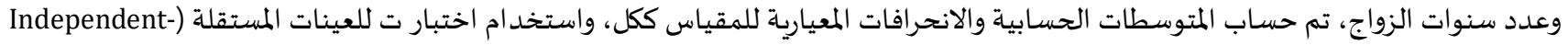
(Samples T-Test

\begin{tabular}{|c|c|c|c|c|c|c|c|}
\hline الدلالة الإحصيائية & درجات الحرية & قيمة "ت" & الانحراف المعياري & المتوسط الحسابي & العدد & الجنس & المقياس \\
\hline \multirow[t]{2}{*}{0.003} & 504.96 & 3.03 & 0.82 & 3.98 & 244 & ذكر & \\
\hline & & & 0.90 & 3.75 & 316 & انثى & \\
\hline
\end{tabular}

يتضح من الجدول (4) واختبار "ت" وجود فروق ذات دلالة إحصائية في مستوى التوافق الزواجي عند مستوى الدلالة (0.05) تعزى لمتغير الجنس لصالح الذكور. يعزو الباحثان النتيجة إلى كون الزواج علاقة بين ذكر وأنثى، ولكل منهما تكوين جسمي وعقلي وعاطفي مختلف عن الآخر، يؤدي ذلك إلى اختلاف

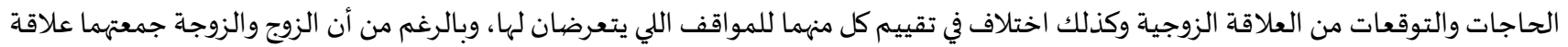



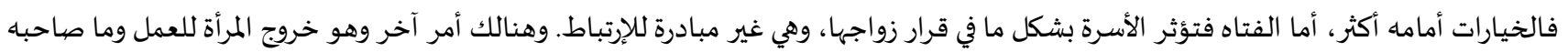
من تأثير على توافقها الزواجي بسبب ازدياد المسؤوليات، بالإضافة إلى أن المرأة تصرح بصوره أكبر عن أي معاناة زوجية تتعرض لهاها، وهي أكثر طلباً 
للمساعدة وذلك بسبب تكوينها البيولوجي والنفسي ولكثرة وصعوبة الأدوار التي تقوم بها أثناء ارتباطها بالعلاقة الزوجية، ولاستقلالها بوظائف تختص بنوع جنسها كالحمل والولادة وما يصياحباء من تكاليف وأعباء.

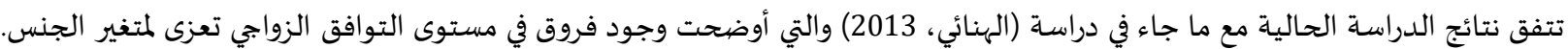
بينما اختلفت نتائج الدراسة الحالية مع نتائج دراسة (الجمالي، 2008)، (التباوي، 2012) و(الخطايبة، 2015) والتي أظهرت عدم وجود فروق دالة إحصائياً في التوافق الزواجي بين الأزواج والزوجات.

فيما يتعلق بمتغير العمر، تم حساب المتوسطات الحسابية والانحرافات المعيارية، كما هو موضح في الجدول (5).

\begin{tabular}{|c|c|c|c|c|}
\hline الانحراف المعياري & المتوسط الحسابي & العدد & العمر & المقياس \\
\hline
\end{tabular}

$\begin{array}{lcccc} & & & \\ 0.97 & 3.73 & 77 & 30 & \\ 0.85 & 3.84 & 282 & 30-39 & \\ 0.89 & 3.88 & 156 & 40-49 & \text { التو افق الزواجي } \\ 0.68 & 4.17 & 25 & 50 \text { أكثر }\end{array}$

يتضح من جدول (5) أن هنالك بعض الفروق الظاهرية في المتوسطات الحسابية بالنسبة للعمر، ومن أجل التأكد من أن هذه الفروق دالة

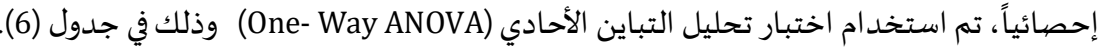

\begin{tabular}{|c|c|c|c|c|c|c|}
\hline مستوى & قيمة & متوسط & درجات & - I la la & - & لה \\
\hline الدلالة & ف & المربعات & الحرية & مجمتوع المربعات & مصندر السباين & الممياس \\
\hline \multirow[t]{4}{*}{0.174} & 1.661 & & & & & \\
\hline & & 1.272 & 3 & 0.29 & يين المجموعات & التو افق \\
\hline & & 0.766 & 536 & 263.11 & داخل المجموعات &  \\
\hline & & & 539 & 263.41 & المحموع الكلى & الزواجي \\
\hline
\end{tabular}

كما يتضح من الجدول (6) عدم وجود فروق ذات دلالة إحصائية في مقياس التوافق الزواجي وفقاً لمتغير العمر.

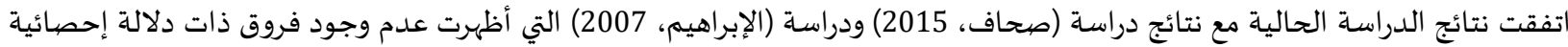
بين متوسطات درجات التوافق الزواجي تعزى لمتغير العمر. بينما تختلف نتائج الدراسة الحالية مع نتائج دراسة (العزة، 2000) التي توصلت إلى أن الفرق الكبير في العمر يؤدي إلى سوء الفهم في الكثير من المجالات مما يؤدي إلى سوء التوافق الزواجي. كما اختلفت مع نتائج دراسـة (الجمالي، 2008) ودراسة (عواودة، 2019) ودراسة (القضاة، 2016) التي أظهرت تأثير عمر الزوجين على درجة التوافق الزواجي.

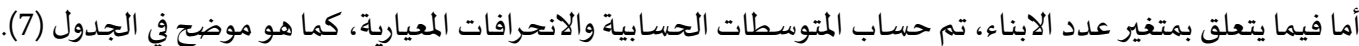
جدول (7): المتوسطات الحسابية والانحر افات المعيارية مقياس التو افق الزواجي وفقاً لمتغيرعدد الابناء

\begin{tabular}{|c|c|c|c|c|}
\hline الانحراف المعياري & المتوسط الحسابي & العدد & العمر & المقياس \\
\hline 970 & & & بدون ابناء & \\
\hline 0.83 & $\begin{array}{l}3.73 \\
3.83\end{array}$ & $\begin{array}{c}46 \\
130\end{array}$ & ابن أو ابنان & \\
\hline 0.89 & 3.83 & 225 & ثلاثة أو أربع ابناء & التو افق الزواجي \\
\hline 0.86 & 3.95 & 139 & خمسة ابناء وأكثر & \\
\hline
\end{tabular}

يتضح من الجدول (7) أن هنالك بعض الفروق الظاهرية في المتوسطات الحسابية بالنسبة لمتغير عدد الابناء، ومن أجل التأكد من أن هذه الفروق دالة إحصائياً، تم استخدام اختبار تحليل التباين الأحادي (One- Way ANOVA) وذلك في جدول (8).

\begin{tabular}{|c|c|c|c|c|c|c|}
\hline مستوى & قيمة & متوسط & درجات & & & \\
\hline الدلالة & ف & المربعات & الحربة & مجمموع المربعات & مصبدر التباين & المقياس \\
\hline 0.40 & 0.98 & $\begin{array}{l}0.75 \\
0.76\end{array}$ & $\begin{array}{c}3 \\
536 \\
539\end{array}$ & $\begin{array}{c}2.25 \\
411.93 \\
414.18\end{array}$ & داخل المجمموعات & الزواجي \\
\hline
\end{tabular}


يتضح من الجدول (8) عدم وجود فروق ذات دلالة إحصائية في مقياس التوافق الزواجي وفقا لمتغير عدد الابناء. وجاءت النتيجة متوافقة مع

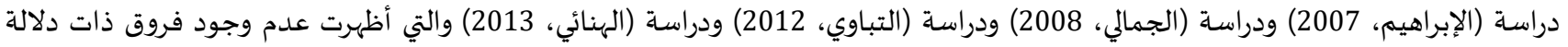
إحصائية في مستوى التوافق الزواجي تعزى لمتغير عدد الابناء.

فيما يتعلق بمتغير عدد سنوات الزواج، تم حساب المتوسطات الحسابية والانحرافات المعيارية، كما هو موضح في الجدول (9). جدول (9): المتوسطات الحسابية والانحر افات المعيارية للتو افق الزواجي وفقاً لمتغير عدد سنوات الزواج

\begin{tabular}{|c|c|c|c|c|}
\hline الانحراف المعياري & المتوسط الحسابي & العدد & عدد سنوات الزواج & المقياس \\
\hline 1.10 & 3.30 & 23 & أول سنة زواج & \\
\hline 0.68 & 4.05 & 85 & $5-2$ & \\
\hline 0.89 & 3.73 & 143 & $10-6$ & التو افق الزواجي \\
\hline 0.89 & 3.90 & 289 & أكثر من 10 سنوات & \\
\hline
\end{tabular}

يتضح من الجدول (9) أن هنالك بعض الفروق الظاهرية في المتوسطات الحسابية بالنسبة لعدد سنوات الزواج، ومن أجل التأكد من أن هذه



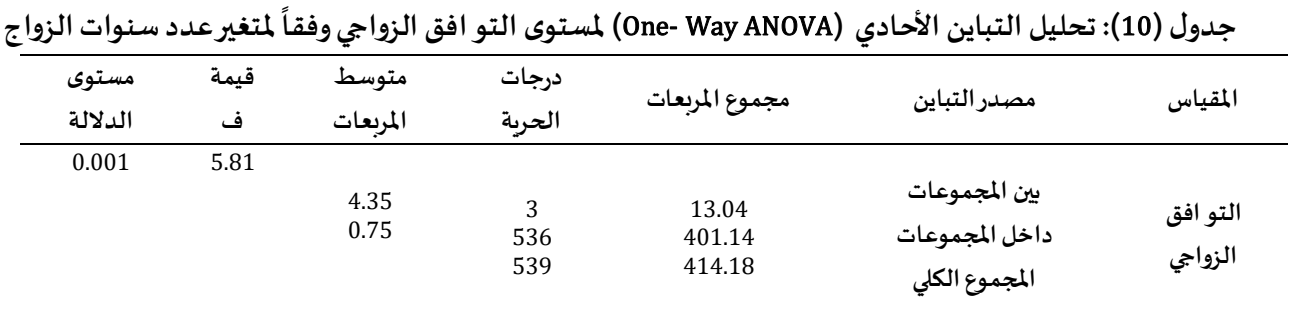

يتضح من الجدول (10) وجود فروق ذات دلالة إحصائية في مقياس التوافق الزواجي، ومن أجل معرفة مصدر الفروق، تم استخدام اختبار

يتضح من خلال الجدول (11) أن هناك فروقاً ذات دلالة إحصائية بين في مستوى التوافق الزواجي بين المتزوجين في السنة الأولى (المتوسط

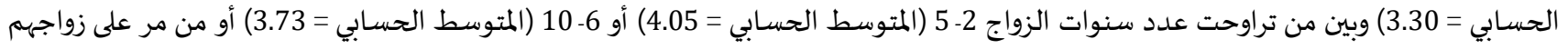
أكثر من 10 سنوات (المتوسط الحسابي = 3.90). حيث تبين بأن زيادة عدد سنوات الزوات تروات تساهم بشكل كبير في زيادة مستوى التوافق الزواجي. ويعزو الباحثان ارتفاع مستوى التوافق الزواجي إلى حاجته لفترة زمنية ليتطور بين الزوجين، حتى يفهم كل منهما الآخر ويشعر بالثقة والقدرة على

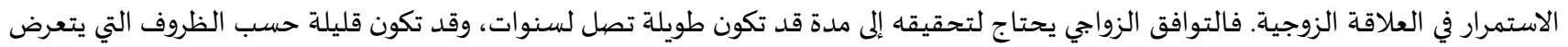
لها الزوجان، حيث تتميز المراحل الأولى بالتقارب الشـديد والاتكال، وتتميز المراحل المتأخرة بالمواجهة والنقاش والتفاوض (الخفاف، 2013). كما يرى

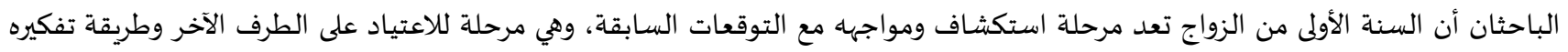

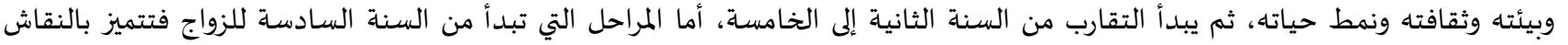
والمواجهة وازدياد المسؤوليات.

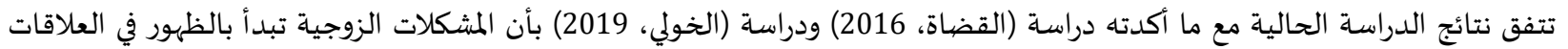
الزوجية خلال الأشهر أو السنوات المبكرة من الزواج، لوجود اختلافات طبيعية في عدة جوانب كالتوقعات حول طبيعة وخصوصية القوانين الزواجية.


عدد سنوات الزواج لصالح الازواج الذين مر على زواجهم عدة سنوات. بينما اختلفت نتائج الدراسة الحالية مع دراسة (الجمالي، 2008) ودراسة

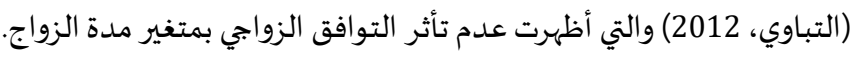

في ضوء النتائج التي تم التوصل إليها، يوصي الباحثان بما يأتي:

لفت نظر العاملين في الإرشاد الزواجي لعمل دورات تدريبية للمتزوجين والمقبلين على الزواج في كيفية رفع مستوى التوافق الزواجي. تطبيق دراسات مماثلة على عينات أخرى وإجراء دراسات مقارنة بين المجتمعات العربية عموماً والمجتمعات الخليجية على وجاء الخصوص. إجراء دراسات أخرى حول مستوى التوافق الزواجي وعلاقته بمتغيرات تصنيفية أخرى مثل الوضع الاقتصادي للزوجين. إجراء دراسات ارتباطية لبحث علاقة مستوى التوافق الزواجي بمتغيرات أخرى كالرضا الزواجي ومهارة حل المشكلات. 
1. الابراهيم، أسماء بدري (2007). علاقة التوافق الزواجي بالمهارات الزواجية وبعض المتغيرات الديموغرافية (رسالة دكتوراه غير منشورة). الجامعة

2. بلميهوب، كلثوم (2010). الاستقرار الزواجي دراسة في سيكولوجية الزواج. مصر: المكتبة العصرية للنشر والتوزيع.

3. البلوي، فهيمة (2015). قدرة العوامل الخمسة الكبرى للشخصية على التنبؤ بالتوافق الزواجي لدى المتزوجات بمنطقة تبوك. (رسالة ماجستير

غير منشورة) جامعة نايف العربية للعلوم الأمنية، السعودية.

4. التباوي، نجمة اللاكي (2012). التوافق الزواجي وعلاقته بضغوط العمل لدى موظفي وموظفات جامعة بنغازي (رسالة ماجستير غير منشورة).

جامعة بنغازي، ليبيا.

5. الجمالي، فوزية (2008). التوافق الزواجي لدى الأزواج العمانيين في ضيوء بعض المتغيرات. مجلة الدراسات التربوية والنفسية: 2(1): 76-97. 6. (رسالة دكتوراه غير منشورة). جامعة وهران. الجزائر.

7. الخطايبة، يوسف ضامن (2015). مقومات التوافق في الحياة الزوجية وعلاقتاه بالعوامل الاجتماعية. مجلة العلوم الإنسانية والاجتماعية:

$.389-371:(2) 42$

8. الخفاف، إيمان عباس (2013). الذكاء الانفعالي. دار المناهج للنشر والتوزيع. عمان: الأردن.



10. الداهري، صالح حسن (2008). أساسيات التوافق النفسي والاضطرابات السلوكية والانفعالية. عمان: دار الصفاء للنشر والتوزيع .

11. الراشد، شذى حمد عبدالله (2016). التوافق الزواجي. الجمعية المصرية للأخصائيين الاجتماعيين: 1(56): 87- 111.

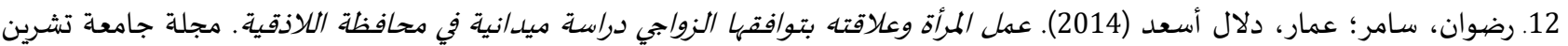

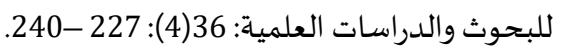

13. زعتر، محمد عاطف (2000). الخصبال الشخصية والتنبؤ بالتوافق الزواجي لدى الشباب. دراسات نفسية. 10(3): 398-443.

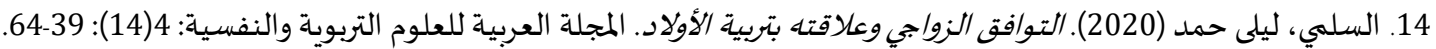

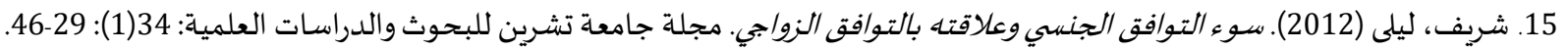

16. الشطي، عدنان (1995). الزواج والعائلة التحليل النفسي والاجتماعي للعلاقات الأسسية. الكويت: مركز الاستشارات السلوكية.

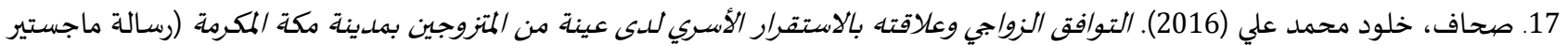

غير منشوره). جامعة أم القرى. السعودية.

18. طلبة، فاديا السيد علي (2002). زواج المماهقات وعلاقته بالتوافق الزواجي. (رسالة ماجستير غير منشورة). كلية التربية. جامعة الزقازيق.

19. عبيد، إيمان محمود (2014). مقياس التوافق الزواجي. مجلة البحث العلمي في التربية: 15(1): 491-506.


21. العزة، سعيد حسني (2000). الإرشاد الأسري. عمان: مكتبة دار الثقافة.

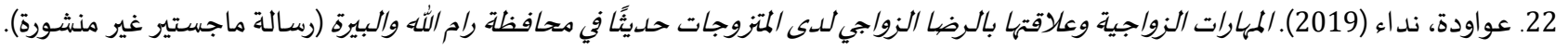
جامعة القدس المفتوحة. فلسطين.

23. القرنى، محمد ضيف الله محمد (2019). الاتجاه نحو الحوار الأسري وعلاقته بالتوافق الزواجي لدى عينة من الأزواج في محافظة بلقرن. إدارة

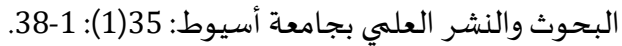

24. القضاة، إنياس نعيم (2016). المهارات الزوجية وعلاقتها بالتوافق الزواجي لدى المتزوجات حلديثا في ملدينة عمان. (رسالة ماجستير غير منشورة). جامعة عمان العربية، الأردن.

25. قمرة، هنادي محمد عمر سراج (2019). التوافق الزواجي وعلاقته بمعايير اختيار شريك الحياة. الجمعية المصرية للقراءة والمعرفة: (215): 311-

26. مرسي، كمال ابراهيم (1999). العلاقة الزوجية والصحة النفسية في الاسلام وعلم النفس (ط2). الكويت: دار القلم للنشر والتوزيع. 
27. https://www.ncsi.gov.om/Pages/NCSI.aspx المركز الوطني للإحصاء والمعلومات (2020). بيانات تعداد 2010. تم الاسترجاع من

28. مهدي، سراي (2012). الاحتراق النفسي وعلاقته بالتوافق الزواجي لدى أساتذة المرحلتين المتوسطة والثانوية. (رسالة ماجستير غير منشورة). جامعة الجزائر، الجزائر. 29. مؤمن، داليا (2008). الأسرة والعلاج الأسري (ط 20). القاهرة: دار السحاب للنشر والتوزيع.

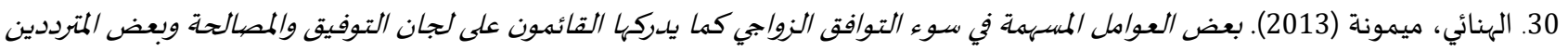

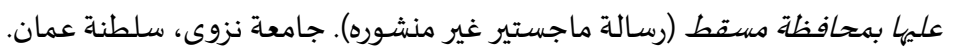

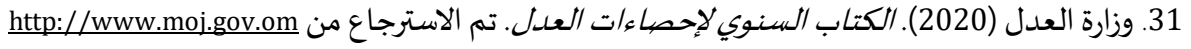

1. Hendrick, S. (1988). A generic measure of relationship satisfaction. Journal of Marriage and the Family, 50(1): 93-98, https://doi.org/10.2307/352430.

2. Locke, H. J., \& Wallace, K. M. (1959). Short marital-adjustment and prediction tests: Their reliability and validity. Marriage and family living, 21(3): 251-255, https://doi.org/10.2307/348022.

3. Spanier, G. B. (1989). Dyadic adjustment scale. Toronto: Multi-Health Systems.

4. Spanier, G. B., \& Cole, C. L. (1976). Toward clarification and investigation of marital adjustment. International Journal of Sociology of the Family, 121-146.

5. Wnoghi, F. (2014). The effect of marital incompatibility on the formation of a tendency to mental illness among women through the application of the MMPI2 test. (unpublished doctoral thesis). Mohamed Khader University, Algeria. 
المجلة الدولية للدراسـات التربوية والنفسية

International Journal of Educational \& Psychological Studies (EPS)

Journal Homepage: https://www.refaad.com/views/EPSR/Home.aspx

wwW.refaad.com

ISSN: 2520-4149 (Online) 2520-4130 (Print)

\title{
The level of marital adjustment among a sample of married couples in the sultanate of Oman and its relationship to demographic variables
}

\section{Iman Hamed Khalfan Al Maqbali}

Social Researcher, College of Arts \& Sciences, University of Nizwa, Oman

\author{
Ahmad MJ 0 Alfawair
}

Associate Professor, College of Arts \& Sciences, University of Nizwa, Oman fawair@unizwa.edu.om

\begin{abstract}
The current study aimed to identify the marital adjustment among a sample of married couples in the Sultanate of Oman. The study sample consists of (540) respondents who were selected randomly as cluster sample. Descriptive design was adopted. Scale of marital adjustment (Hendrick, 2013) was used. The results showed that the level of marital adjustment was high. According to variables, the results showed that there were significant differences in the level of marital adjustment due to gender variable in favor of males; and there were significant differences in the level of marital adjustment due to years of marriage variable in favor of who have been married for 2 to 5 years. According to age and number of children variables, the results showed that there were no significant differences in the level of marital adjustment due to gender or number of children.
\end{abstract}

Keywords: Marital adjustment; family; marriage; marital relations; Married.

\section{References:}

1. 'byd, Eyman Mhmwd (2014). Mqyas Altwafq Alzwajy. Mjlt Albhth Al'lmy Fy Altrbyh: 15(1): 491-506.

2. Al'tyby, Tarq Mwsa (2006). Alsra'at Altnzymyh Wasalyb Alt'aml M'eha. (Rsalt Majstyr Ghyr Mnshwrh). Jam't Nayf Al'rbyh Ll'lwm Alamnyh.

3. 'wawdh, Nda' (2019). Almharat Alzwajyh W'laqtha Balrda Alzwajy Lda Almtzwjat Hdythana Fy Mhafzt Ram Allh Walbyrh (Rsalt Majstyr Ghyr Mnshwrh). Jam't Alqds Almftwhh. Flstyn.

4. Al'zh, S'yd Hsny (2000). Alershad Alasry. 'man: Mktbh Dar Althqafh.

5. Alabrahym, Asma' Bdry (2007). 'laqt Altwafq Alzwajy Balmharat Alzwajyh Wb'd Almtghyrat Aldymwghrafyh (Rsalt Dktwrah Ghyr Mnshwrh). Aljam'h Alardnyh. Alardn.

6. Blmyhwb, Klthwm (2010). Alastqrar Alzwajy Drash Fy Sykwlwjyt Alzwaj. Msr: Almktbh Al'sryh Llnshr Waltwzy'.

7. Alblwy, Fhymh (2015). Qdrh Al'waml Alkhmsh Alkbra Llshkhsyh 'la Altnb' Baltwafq Alzwajy Lda Almtzwjat Bmntqt Tbwk. (Rsalt Majstyr Ghyr Mnshwrh) Jam't Nayf Al'rbyh Ll'lwm Alamnyh, Als'wdyh.

8. Aldahry, Salh Hsn (2008). Asasyat Altwafq Alnfsy Waladtrabat Alslwkyh Walanf'alyh. 'man: Dar Alsfa' Llnshr Waltwzy'.

9. Alhna'y, Mymwnh (2013). B'd Al'waml Almshmh Fy Sw' Altwafq Alzwajy Kma Ydrkha Alqa'mwn 'la Ljan Altwfyq Walmsalhh Wb'd Almtrddyn 'lyha Bmhafzt Msqt (Rsalt Majstyr Ghyr Mnshwrh). Jam't Nzwa, Sltnh 'man.

10. Hwly, Fatmh (2019). Altwafq Alzwajy Llwaldyn Kma Ydrkh Alabna' W'laqth Balthsyl Aldrasy Lda Tlamyd Alsnh Alrab'h Mn Alt'lym Almtwst. (Rsalt Dktwrah Ghyr Mnshwrh). Jam't Whran. Aljza'r.

11. Aljmaly, Fwzyh (2008). Altwafq Alzwajy Lda Alazwaj Al'manyyn Fy Dw' B'd Almtghyrat. Mjlt Aldrasat Altrbwyh Walnfsyh: 2(1): 76-97. 
12. Alkhfaf, Eyman 'bas (2013). Aldka' Alanf'aly. Dar Almnahj Llnshr Waltwzy'. 'man: Alardn.

13. Alkhtaybh, Ywsf Damn (2015). Mqwmat Altwafq Fy Alhyah Alzwjyh W'laqth Bal'waml Alajtma'yh. Mjlt Al'lwm Alensanyh Walajtma'yh: 42(2): 371 - 389.

14. Alkhwly, Sna' (2001). Alasrh Walhyah Al'a'lyh. 'man: Dar Almsyrh Llnshr Waltwzy' Waltba'h.

15. M'mn, Dalya (2008). Alasrh Wal'laj Alasry (T2). Alqahrh: Dar Alshab Llnshr Waltwzy'.

16. Mhdy, Sray (2012). Alahtraq Alnfsy W'laqth Baltwafq Alzwajy Lda Asatdh Almrhltyn Almtwsth Walthanwyh. (Rsalt Majstyr Ghyr Mnshwrh). Jam't Aljza'r, Aljza'r.

17. Almrkz Alwtny Llehsa' Walm'lwmat (2020). Byanat T'dad 2010. Tm Alastrja' Mn https://www.ncsi.gov.om/pages/ncsi.aspx

18. Mrsy, Kmal Abrahym (1999). Al'laqh Alzwjyh Walshh Alnfsyh Fy Alaslam W'Im Alnfs (T2). Alkwyt: Dar Alqlm Llnshr Waltwzy'.

19. Alqdah, Enyas N'ym (2016). Almharat Alzwjyh W'laqtha Baltwafq Alzwajy Lda Almtzwjat Hdytha Fy Mdynt 'man. (Rsalt Majstyr Ghyr Mnshwrh). Jam't 'man Al'rbyh, Alardn.

20. Qmrh, Hnady Mhmd 'mr Sraj (2019). Altwafq Alzwajy W'laqth Bm'ayyr Akhtyar Shryk Alhyah. Aljm'yh Almsryh Llqra'h Walm'rfh: (215): 311-336.

21. Alqrna, Mhmd Dyf Allh Mhmd (2019). Alatjah Nhw Alhwar Alasry W'laqth Baltwafq Alzwajy Lda 'ynh Mn Alazwaj Fy Mhafzt Blqrn. Edart Albhwth Walnshr Al'Imy Bjam't Asywt: 35(1): 1-38.

22. Alrashd, Shda Hmd 'Ebdallh (2016). Altwafq Alzwajy. Aljm'yh Almsryh Llakhsa'yyn Alajtma'yyn: 1(56): 87- 111.

23. Rdwan, Samr: 'mar, Dlal As'd (2014). 'ml Almrah W'laqth Btwafqha Alzwajy Drash Mydanyh Fy Mhafzt Alladqyh. Mjlt Jam't Tshryn Llbhwth Waldrasat Al'Imyh: 36(4): 227 -240.

24. Shaf, Khlwd Mhmd 'ly (2016). Altwafq Alzwajy W'laqth Balastqrar Alasry Lda 'ynh Mn Almtzwjyn Bmdynt Mkh Almkrmh (Rsalt Majstyr Ghyr Mnshwrh). Jam't Am Alqra. Als'wdyh.

25. Shryf, Lyla (2012). Sw' Altwafq Aljnsy W'laqth Baltwafq Alzwajy. Mjlt Jam't Tshryn Llbhwth Waldrasat Al'lmyh: 34(1): 29-46.

26. Alshty, 'dnan (1995). Alzwaj Wal'a'lh Althlyl Alnfsy Walajtma'y Ll'laqat Alasryh. Alkwyt: Mrkz Alastsharat Alslwkyh.

27. Alslmy, Lyla Hmd (2020). Altwafq Alzwajy W'laqth Btrbyh Alawlad. Almjlh Al'rbyh Ll'lwm Altrbwyh Walnfsyh: 4(14): 39-64.

28. Altbawy, Njmh Allaky (2012). Altwafq Alzwajy W'laqth Bdghwt Al'ml Lda Mwzfy Wmwzfat Jam't Bnghazy (Rsalt Majstyr Ghyr Mnshwrh). Jam't Bnghazy, Lybya.

29. Tlbh, Fadyh Alsyd 'ly (2002). Zwaj Almrahqat W'laqth Baltwafq Alzwajy. (Rsalt Majstyr Ghyr Mnshwrh). Klyt Altrbyh. Jam't Alzqazyq.

30. Wzart Al'dl (2020). Alktab Alsnwy Lehsa'at Al'edl. Tm Alastrja' Mn http://www.moj.gov.om

31. Z'tr, Mhmd 'atf (2000). Alkhsal Alshkhsyh Waltnb' Baltwafq Alzwajy Lda Alshbab. Drasat Nfsyh. 10(3): 398-443. 